\title{
TRIBOLOGICAL ASPECTS OF PLASMA NITRIDED LAYER IN THE CASE OF A NON- CONVENTIONAL TREATED STEEL FOR INDUSTRIAL GEARINGS
}

\author{
Carmen-Penelopi PAPADATU ${ }^{1}$ \\ ${ }^{1}$ Dunarea de Jos University of Galati, 47 Domneasca street, 800080, Romania, EU, \\ papadatu.carmen@yahoo.com
}

https://doi.org/10.37904/metal.2020.3555

\begin{abstract}
Plasma nitriding applied after a non-conventional treatment in magnetic field to the steel used in industry, have been studied in this paper. It have been demonstrated that the energy of the magnetic field intervenes in the balance of the global power of the phase transformations in solid state altering the thermodynamics, kinetics and the mechanisms of processes, the structures and some properties of the steel. The samples have been tested using an Amsler stand for wear tests (dry friction) and the diffractometric analysis completed this study. The plasma nitriding plant used was named the INI 150, was made by the Institute of Radiation Physics and Technology in collaboration with the "Electrotechnics" Enterprise and the Nuclear Apparatus (ICEFIZ) from Romania and was destined for technological research, but can also be used for industrial nitriding of small pieces. INI 150 was based on the physical phenomenon of a double cathode at plasma (ion) nitriding. The paper is a review of my researches from the last years.
\end{abstract}

Keywords: Plasma nitriding, thermo-magnetic treatment, steel, wear tests

\section{INTRODUCTION}

Process of ion/plasma nitriding, also known as glow discharge nitriding, was implemented into industrial practice in the 1960's and 1970's. The first commercial applications have been made in the 1930's and in the Second World War, taking account the Berghaus Patent since 1938 [1]. Plasma nitriding is a thermo-chemical treatment with diffusion process and the interaction of the nitrogen with the basic material - a steel grade hardened and tempered - lead to structural constituents whose nature determines a major hardness of the nitrided layers. The thermo-chemical treatment modifies the grain limit and the resistance of the steel. For instance, the mechanical properties of the steel -as the wear process- can be significantly improved and the hardness of the tool steels can be double on the surface.

In this paper was studied the effect of the magnetic field applied on the improvement treatments before the ionic nitriding. A thermo-magnetic treatment applied before plasma nitriding modifies the characteristics of the mechanical resistance of the steel, the hardness and the resistance of the corrosion process. The magnetic field applied during the part of the improvement treatment of the steel grade lead to appear mechanical oscillations triggered by Magnetostriction. The energy of the magnetic field may intervene in the balance of global power of the phase transformations of solid state altering the thermodynamics, kinetics and the mechanisms, the structures and properties of the steels [2,3,5]. The magnetic field applied leads to a decreasing of the residual austenite amount (Arez) during the annealing/hardening treatment of the gearing or tools steels, according to the literature [5]. According to [2,3,5], was calculated that $30 \%$ of Residual Austenite (Arez) in a hardened steel with $1.1 \% \mathrm{C}$ and $8 \% \mathrm{Ni}$ contents, was transformed by returning to $36{ }^{\circ} \mathrm{C}$ in 30 minutes, while the same steel with the same amount of the residual Austenite was transformed by the treatment in magnetic field by returning to $360^{\circ} \mathrm{C}$ in 24 minutes. Sputtering is a phenomenon that can be finds at the interaction of the glow discharge with the cathode. The pressure of the gases in plasma nitriding process ranges between 0.1 and 5.0 mbar. The sputtered atoms circulate above the cathode in the form of a dust [7]. 
Some of the atoms are redeposited on the cathode while others are dispersed in the system [6,7]. But it is possible that this phenomenon can provokes an excess of atoms which want to return to the surface and this situation might be detrimental of the nitriding process [8]. The mechanism of heat transfer during heating of the cathode in a glow discharge is very complex.

In this short review of the own researches in the non-conventional treatments in magnetic field domain, it have been demonstrated that a magnetic field which is overlapped during the cooling in case of the heat treatments determines the modification of the structure of the material.

\section{MATERIAL AND EXPERIMENTAL PART}

For the experimental procedure, the samples have been realized as rollers from a steel grade for improvement treatment for machine parts construction with the following principal content: $0.42 \% \mathrm{C}, 0.02 \% \mathrm{Al}, 1.02 \% \mathrm{Cr}$, $0.17 \% \mathrm{Mo}, 0.68 \% \mathrm{Mn}, 0.22 \% \mathrm{Cu}, 0.33 \% \mathrm{Si}, 0.26 \% \mathrm{Ni}, 0.030 \% \mathrm{P}, 0.026 \% \mathrm{~S}$. The first part from the complex program of treatments consisted of thermo-magnetic treatments. The second part of the treatments consists in the applying the thermo-chemical treatment in plasma. There are mentioned the following treatments which have been selected for different samples: Treatment $\mathrm{T} 1$ represents a hardening at $850{ }^{\circ} \mathrm{C}$ and a high tempering treatment at $580^{\circ} \mathrm{C}$, with cooling in water - being the classic improvement treatment followed by a plasma nitriding at $530{ }^{\circ} \mathrm{C}$; Treatment $\mathrm{T} 2$ represents a complete martensitic hardening in weak alternative magnetic field with the intensity $\mathrm{H}=920 \mathrm{~A} / \mathrm{m}$ and a high tempering with cooling in water in strong magnetic field, followed by a plasma nitriding treatment at $530{ }^{\circ} \mathrm{C}$; The Treatment T3 represents a martensitic hardening and a high tempering with cooling in water in strong magnetic field (alternative current), followed by a plasma nitriding treatment at $530^{\circ} \mathrm{C}$. Plasma nitriding process had a duration by seven hours, depending by the dimensions of the samples $[3,11]$. The third part of the experimental program consists in dry wear tests, friction processes realized with an Amsler machine. The samples have been analyzed using the diffractometric analysis which completed this study.

\section{RESULTS AND DISCUSSION}

After every hour of wear tests, the samples were subjected to diffractometric Analysis. In Figures 1 - $\mathbf{3}$ were presented difractometric aspects regarding the plasma nitrided layer in the cases of the treatments $\mathrm{T} 1, \mathrm{~T} 2$ and T3 [3].

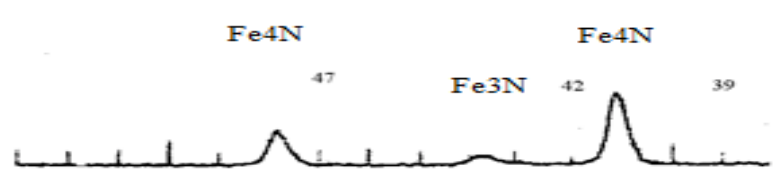

Figure 1 Diffractometric fragment corresponding to nitrided layer in the case of T1 classic treatment

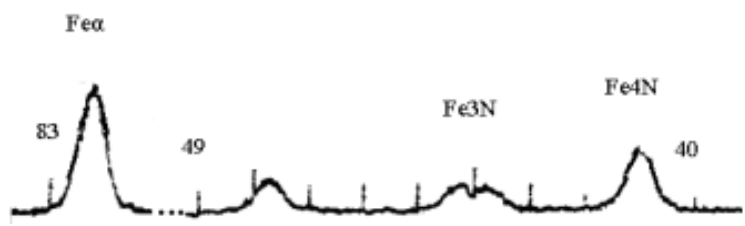

Figure 3 Diffractometric aspects corresponding to the samples subjected to non-conventional treatment T3

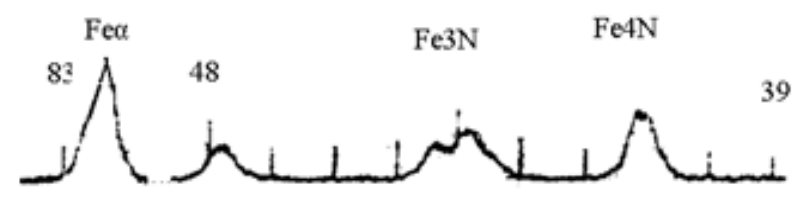

Figure 2 Diffractometric aspects corresponding to the samples subjected to non-conventional treatment T2

It can be observed that in the case of non-conventional treatments in magnetic field applied before plasma nitriding, the amount of $\mathrm{Fe}_{3} \mathrm{~N}$ and Fea (M) in superficial layer increased. This is a reason to observe that the nonconventional treatment - an improvement treatment in magnetic field - applied before thermo-chemical treatment determines the increasing of the hardmess and the wear resistance of the steel. 
In Figures 1 - 3, in the case of the samples treated with T2 treatment, the amount of martensite is highest compared to other samples (corresponding to T1 or T3 treatment). The percentage of carbon (\% $\mathrm{C}$ ) being the average for the analyzed steel (up to $0.6 \%$ ), the evolution of the degree of tetragonality of martensite in certain processes or over time can be controlled by the evolution of the diffraction line $(211)[2,3,11]$.

In Figure 4 was presented the evolution of the micro-hardness (Vickers) of the steel, in the case of nonconventional treatments T2 and T3. The thickness of the white (nitrided) layer (DGR1) increased in the cases of non-conventional treatments T2 and T3. The morphology of the nitrided layers depends on the core microstructure resulting from the transformation of chromium carbides into chromium nitrides. Microstructures must be stable during the nitriding treatment.

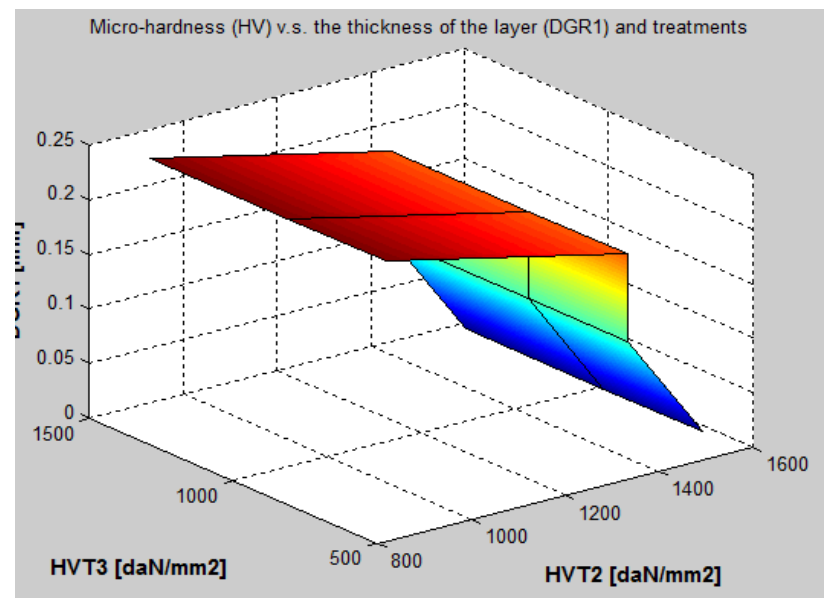

Figure 4 Microhardness (HV) versus the thickness of the superficial layers (DGR1) in the cases of the non-conventional treatments T2 and T3
Notations: HVT2 = micro-hardness of the samples treated with T2 treatment; HVT3 = micro-hardness of the samples treated with T3 treatment;GDR1 = the thickness of the plasma nitride layer.

The mechanical properties of the nitrided layers are directly linked to the microstructure and precipitation phenomena that occur during nitrogen diffusion. With the increasing of the hardness, the compressive residual stresses are generated due to phase transformation and/or precipitation. Three hours of wear tests have been applied after plasma nitriding. After each hour have been made diffractometric analysis on Dron 3 from Faculty of Engineering Laboratory, Dunarea de Jos University, Galati, Romania.

In Figures $\mathbf{5}(\mathbf{a}, \mathbf{b}, \mathbf{c}$,$) were presented the distribution of the phases in superficial layers in three cases: Classic$ treatment without magnetic field (T1), non-conventional treatment totally in magnetic field followed by plasma nitriding (T2) and in case of non-conventional treatment with cooling in magnetic field-Alternative Current followed by plasma nitriding (T3). The properties of the nitrided layer depend on the nature of the nitride phases. With the increase in nitriding temperature, the duration of nitration is reduced, but the hardness of the nitrided layer decreases due to the coalescence of the alloying elements. Studying fragments from diffractograms, the following aspects have been observed: the evolution of residual austenite (A rez) - which is on diffractograms between the odds: $38^{\circ}-47^{\circ}$, martensite $(\mathrm{M})$ - located in the range: $81^{\circ}-92^{\circ}$ and a series of nitrides that improve through their presence in the thermo-chemically treated surface layer by ionic nitration, the wear resistance characteristics of the analyzed steel. The martensitic phase - in the range $\left(44^{\circ}-45^{\circ}\right)$ - in the superficial nitride layer, besides the $\mathrm{Fe}_{3} \mathrm{~N}$ and $\mathrm{Fe}_{4} \mathrm{~N}$ phases, provides the layer with a good hardness and a wear resistance higher than the investigated samples treated classically.

Martensite $(M)$ is a tough constituent, and the martensite with nitrogen (phase $\alpha$ ) is the most durable and hardness phase in the nitrided layer $[3,10,11]$. Martensite is a solid carbon solution in Fea, which has a large amount of dissolved carbon, giving it a high hardness. It is worth noting that the $\mathrm{Fe}_{2} \mathrm{~N}(\xi)$ phase - which has a rhombic structure (deformed structure of the phase $\varepsilon$ ) and a low hardness, does not appear in the structure of the studied steel. Within the accuracy limits of the DRON 3 diffractometer, there was no evidence of this phase. Due to friction wear tests, it was possible to study the depth distribution of the $\mathrm{Fe}_{3} \mathrm{~N}$ and $\mathrm{Fe}_{4} \mathrm{~N}$ phases in the superficial layer. The distribution of $\mathrm{Fe}_{3} \mathrm{~N}$ and $\mathrm{Fe}_{4} \mathrm{~N}$ phases on the plasma nitrided layer is uneven, which demonstrates that, no matter how careful we are, the nitriding process does not flow uniformly, being influenced by several factors, especially the nature of the nitrided material. 


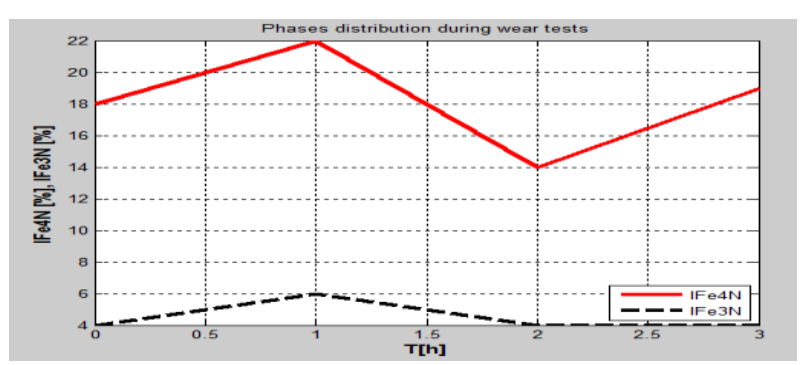

a)

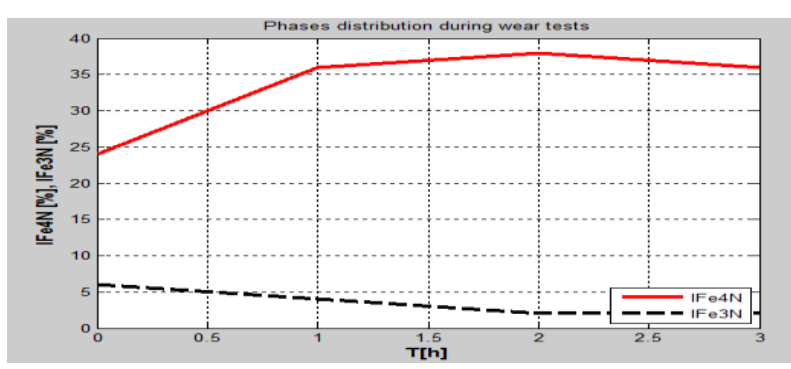

b)

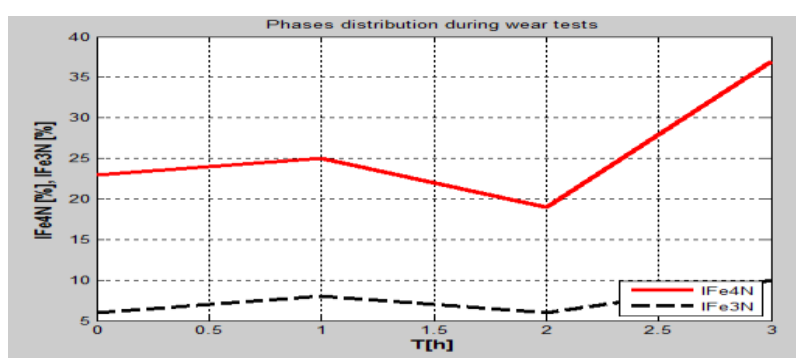

c)

Figure 5 Phases distribution ( $\mathrm{I}_{\mathrm{Fe} 4 \mathrm{~N}} \mathrm{I}_{\mathrm{Fe} 3 \mathrm{~N}}$ ) in the superficial layer, after plasma nitriding process for the samples: a) subjected to $\mathrm{T} 1$ treatment, during wear tests for $Q=750 \mathrm{~N}, \xi=10 \%$ [3]; b) subjected to T3 treatment, during wear tests for $Q=750 \mathrm{~N}, \xi=10 \%$; c) subjected to $T 1$ treatment, during wear tests for $Q$ $=1500 \mathrm{~N}, \xi=20 \%$.

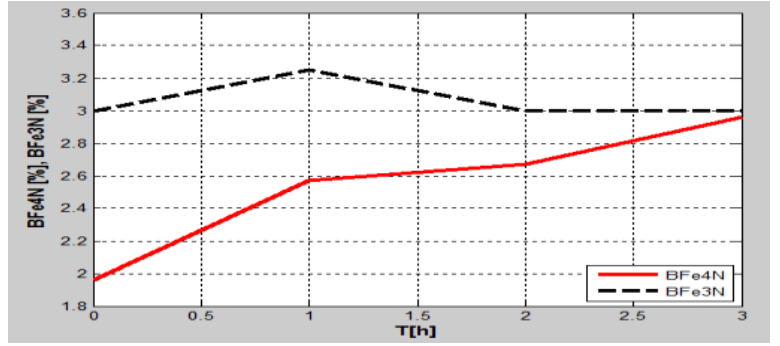

a)

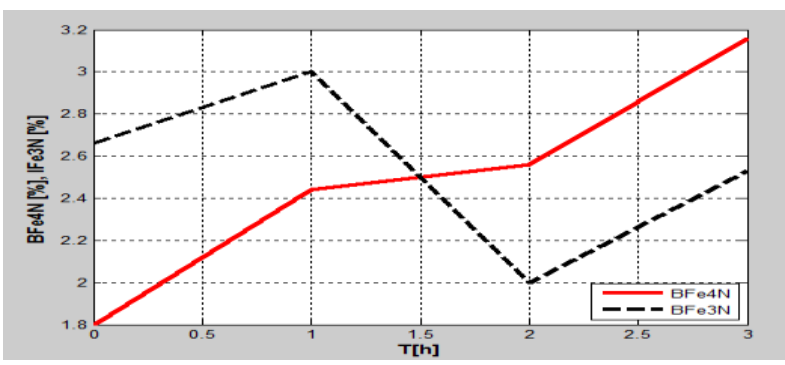

b)

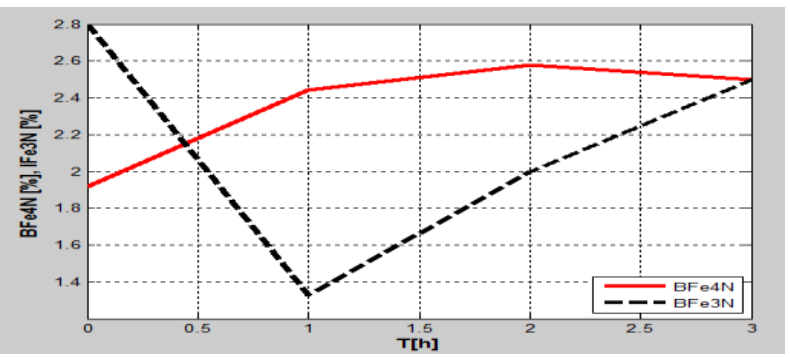

c)

Figure 6 Internal tensions of second order $\left(\mathrm{B}_{\mathrm{Fe}} \mathrm{N}\right.$; $\mathrm{B}_{\mathrm{Fe} \mathrm{N} N}$ ) in the superficial layer after plasma nitriding process, for samples: a) subjected to T1 treatment, during three hours of wear tests for $Q=1500 \mathrm{~N}, \xi=$ $10 \%$; b) subjected to $\mathrm{T} 1$ treatment, during three hours of wear tests for $\mathrm{Q}=750 \mathrm{~N}, \xi=10 \% ; \mathrm{c}$ ) subjected to $\mathrm{T} 2$, for $\mathrm{Q}=750 \mathrm{~N}, \xi=10 \%$.

The tensions of second order corresponding to the $\mathrm{Fe}_{3} \mathrm{~N}$ phase no longer have a high cyclical magnitude as for the non-magnetic field treated samples. This variation can be considered a branch of a cyclical variation (oscillating), but this fatigue stress cycle is much lower than the classically treated samples, stretching over a much longer wear load interval (see Figures $\mathbf{6} \mathbf{a}, \mathbf{b}, \mathbf{c}$ ). Therefore, the "fatigue" of the $\mathrm{Fe}_{3} \mathrm{~N}$ phase is greatly reduced and eliminates the possibility of exfoliating the hard layer - plasma nitrided, the sample behaving very well in the friction wear - times much longer than the classic treated sample. At the same time, a change in the distribution of the $\mathrm{Fe}_{4} \mathrm{~N}$ phase comparing to $\mathrm{Fe}_{3} \mathrm{~N}$ in the superficial layer is observed. Thus, at the classically treated sample, the distribution is cyclic, the greater evolution is at the $\mathrm{Fe}_{4} \mathrm{~N}$ comparing to $\mathrm{Fe}_{3} \mathrm{~N}$ phase, which gives the superficial layer a hardness and resistance to wear $\left(\mathrm{Fe}_{4} \mathrm{~N}\right.$ phase being a hard phase, more than $\mathrm{Fe}_{3} \mathrm{~N}$ ). In the $\mathrm{T} 2$ - treated sample case, the evolution of the $\mathrm{Fe}_{3} \mathrm{~N}$ and $\mathrm{Fe}_{4} \mathrm{~N}$ phases in the plasma nitrided layer is evenly increasing - especially in the case of $\mathrm{Fe}_{4} \mathrm{~N}$ - which is a positive thing regarding the increase of the wear resistance and the hardness of the nitrided layer, while the evolution of the distribution the $\mathrm{Fe}_{3} \mathrm{~N}_{\text {phase }}$ is down. In table 1 have been presented results of the researches corresponding to classic treatment (T1) and a non-conventional treatment (T2) [3]. 
Table 1 Results corresponding to classic treatment (T1) and a non-conventional treatment (T2)

\begin{tabular}{|c|c|c|c|c|c|c|c|c|c|}
\hline $\begin{array}{c}\text { Code } \\
\text { samples }\end{array}$ & $\begin{array}{l}\sim \% \\
\mathrm{I}_{\mathrm{Fe} 3 \mathrm{~N}} \\
\end{array}$ & $\begin{array}{c}\sim \sigma_{\mathrm{II}} \\
\mathrm{B}_{\mathrm{Fe} 3 \mathrm{~N}}\end{array}$ & $\begin{array}{l}\sim \% \\
\mathrm{I}_{\mathrm{Fe} 4 \mathrm{~N}} \\
\end{array}$ & $\begin{array}{c}\sim \sigma_{\| I} \\
\mathrm{~B}_{\mathrm{Fe} 4 \mathrm{~N}}\end{array}$ & $\begin{array}{l}\sim \mathrm{C} / \mathrm{a} \\
\mathrm{B}_{211}\end{array}$ & $\begin{array}{c}\mathbf{t} \\
{[\mathrm{h}]}\end{array}$ & $\begin{array}{c}\mathbf{Q} \\
{[\mathrm{daN}]}\end{array}$ & $\begin{array}{c}\xi \\
{[\%]}\end{array}$ & Treatment \\
\hline 1.2 & 4 & 2.66 & 18 & 1.80 & 0.896 & 0 & - & - & $\mathrm{T} 1$ \\
\hline 1.2 & 6 & 3.00 & 22 & 2.44 & 0.894 & 1 & 75 & 10 & $\mathrm{~T} 1$ \\
\hline 1.2 & 4 & 2.00 & 14 & 2.56 & 0.894 & 2 & 75 & 10 & $\mathrm{~T} 1$ \\
\hline 1.2 & 4 & 2.53 & 19 & 3.16 & 0.893 & 3 & 75 & 10 & $\mathrm{~T} 1$ \\
\hline 2.2 & 14 & 2.80 & 14 & 1.92 & 2.22 & 0 & - & - & $\mathrm{T} 2$ \\
\hline 2.2 & 14 & 1.33 & 22 & 2.44 & 2.51 & 1 & 75 & 10 & $\mathrm{~T} 2$ \\
\hline 2.2 & 10 & 2.00 & 22 & 2.58 & 2.05 & 2 & 75 & 10 & $\mathrm{~T} 2$ \\
\hline 2.2 & 10 & 2.5 & 15 & 2.50 & 2.54 & 3 & 75 & 10 & $\mathrm{~T} 2$ \\
\hline
\end{tabular}

Studying the Table 1, it can be observed that the degree of tetragonality of martensite (c/a) values for the samples treated with T2 treatment, resulted from the calculations, are highest compared to the samples that have been treated without magnetic field. In Figures $\mathbf{7 a}$ and $\mathbf{7 b}$ have been presented Phases distribution (IFe4N), Internal tensions of second order (BFe4N) and the degrees of tetragonality of Martensite (c/a) in the superficial layer, after plasma nitriding for T1 case respectively, for T2 non-conventional treatment.

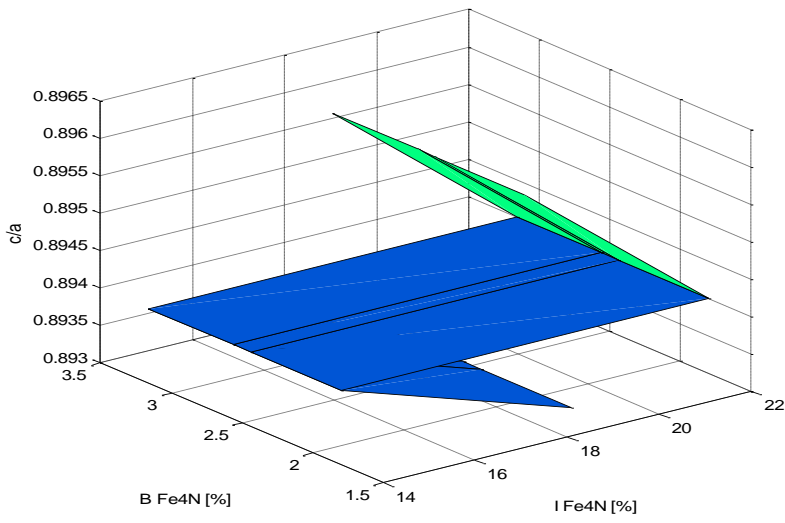

Figure 7a Phases distribution (IFe4N), Internal tensions of second order (BFe4N) and the tetragonality degrades of Martensite (c/a) in the superficial layer, for $\mathrm{T} 1$ classic treatment

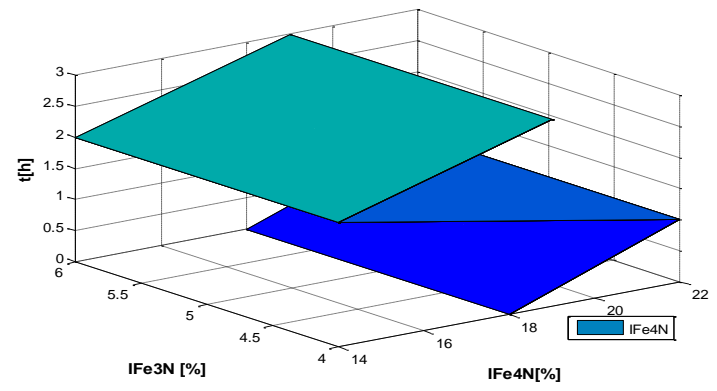

Figure 8a Phases distribution (IFe4N and Fe3N), in the superficial layer, for $\mathrm{T} 1$ classic treatment

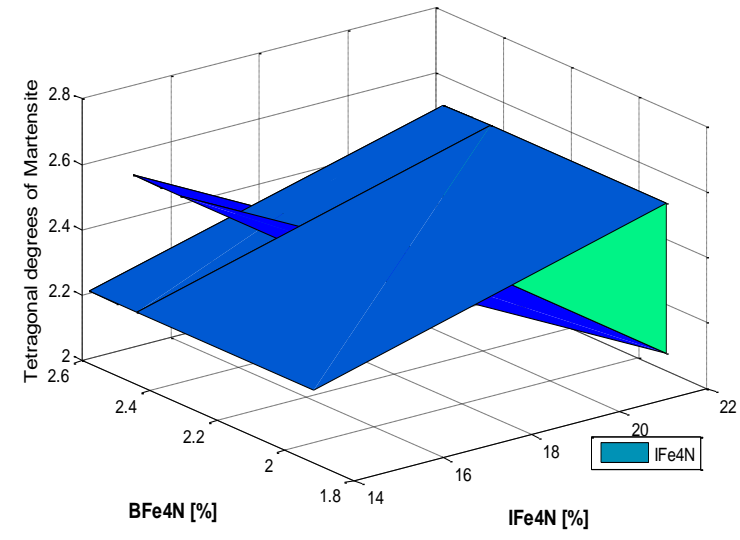

Figure $7 \mathbf{b}$ Phases distribution (IFe4N), Internal tensions of second order (BFe4N) and the degrees of tetragonality of Martensite (c/a) in the superficial layer, for T2 non-conventional treatment

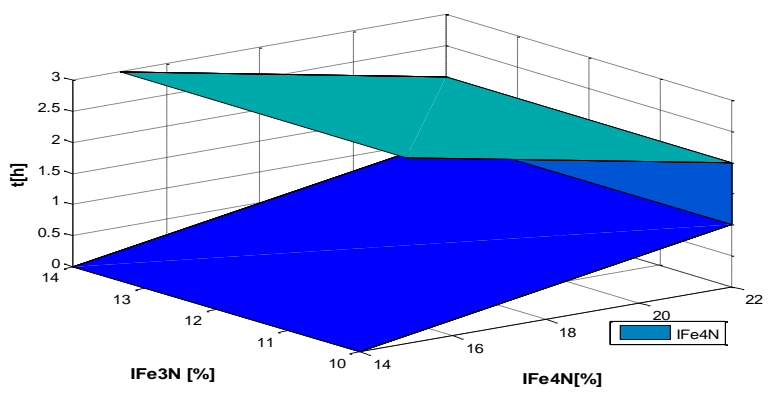

Figure 8 b Phases distribution (IFe4N and Fe3N), in the superficial layer, for $\mathrm{T} 2$ treatment 
In Figures $\mathbf{8} \mathbf{a}$ and $\mathbf{8} \mathbf{b}$ are presented phases distribution $\left(\mathrm{IFe}_{4} \mathrm{~N}\right.$ and $\left.\mathrm{Fe}_{3} \mathrm{~N}\right)$, in the superficial layer, after plasma nitriding for $\mathrm{T} 1$ classic treatment respectively, for $\mathrm{T} 2$ non-conventional treatment.

\section{CONCLUSIONS}

Through applying a magnetic field - alternative current - in some specific conditions, on the heat treatment applied before the plasma nitriding process, finally, the quantity of the $\mathrm{Fe}_{3} \mathrm{~N}$ phase decreased, the quantity of $\mathrm{Fe}_{4} \mathrm{~N}$ increased in the plasma nitrided layer and the distribution of these phases during wear tests implies an increasing of the wear resistance and an improvement of the mechanical properties of the superficial layer of the steel. After the non-conventional treatment applied, in the case of the treatment T2 - the micro-hardness of the superficial layer of steel after thermo-chemical treatment increased with approx. $20-30 \%$, depending on the treatment regime applied, comparing to the classic treatment applied. From the diffractometric point of view, the samples present changes of the content of $\mathrm{Fe}_{3} \mathrm{~N}$ and $\mathrm{Fe}_{4} \mathrm{~N}$ phases in the superficial layer thermochemically treated. This situation implies changes in micro-hardness of the superficial layers. Magnetic field influences positively the mechanical properties of the steel.

\section{ACKNOWLEDGEMENTS}

This work started during the preparing my doctoral Thesis and the tests continues after the end of Doctoral program. The experimental program have been made in Romania, the wear tests, diffractometric analysis and micro-structural aspects have been made at Dunarea de Jos University from Galati. Thermo-magnetic treatments have been made at Transilvania University Laboratory from Brasov, Romania.

\section{REFERENCES}

[1] BERGHAUS, B., UK Patent 510,993: Improvements in and relating to the coating of articles by means of thermally vaporized material, Patent UK 510, 993, 1938.

[2] GHEORGHIES $C$ and STEFANESCU, I. Effects of Thermomagnetic Treatment on Microstructure and Mechanical Properties of Rolling Bearing Steel, Journal of Iron and Steel Research, International, 17 (9), pp.46-52, 2010; Available from: https://doi.org/10.1016/S1006-706X(10)60141-0, DOI: 10.1016/S1006 -706X(10)60141-0.

[3] PAPADATU, C. P., Posibilitati de imbunatatire a calitatii unor oteluri utilizate in industria metalurgica, Dunarea de Jos University Publishing House, Galati, Romania, ISBN: 978-973-627-371-1, 2006.

[4] PAPADATU, C. P., SANDU, A., BORDEI, M., SANDU, G. Study on the Influence of the Treatment in Magnetic Field on the Nitrided Layer in Plasma, Revista de Chimie, 2017, 68, 675- 679, WOS: 000400732400009.

[5] BALTES, L., FLOREA, R., MARKOS, Z. - Influence of the thermo-magnetic treatments on the durability of drills from Rp5 steel, International Conference on Materials Science Proceeding BRAMAT Brasov, 2001, pp.325.

[6] MITTEMEIJER, E.J., Steel Heat Treating Fundamentals and Processes in J. Dossett, G.E. Totten (Eds.), ASM Handbook, ISBN-13: 978-1-62708-011-8, Volume 4A, 2013.

[7] MERLINO, R. L. and GOREE, J. A., Dusty plasmas in the laboratory industry, and space, Physics Today, July, 32-38, 2004.

[8] ROLIŃSKI E, SHARP G, BRONDUM K and PETERSON N (2005a), 'P/M turbo charger and armature components: plasma nitriding and nitrocarburizing to reduce friction wear', SAE World Congress, Detroit, MI, 1114 April, Paper 2005- 01-0722, Warrendale, PA, SAE International, 2005.

[9] CAVAliere, P., PERRONE, A., SILVELLO, A., Engineering Science and Technology, 2016, 19, 292.

[10] KOSTA-KRÄMER, BORSA D M at al. Physical Review (The American Physical Society), 2004, B 69 (14), 2004 , pp.144402-1- 144402-8.

[11] PAPADATU, C.P., IOP Conference Series: Materials Science and Engineering, 2017, vol 174, 2017, Art..01201, Available from: http://iopscience.iop.org/article/10.1088/1757-899X/174/1/012014/meta. DOI:10.1088/1757$899 X / 174 / 1 / 012014$. 